\title{
Interações sociais e novos padrões perceptivos na construção da subjetividade
}

Denise Azevedo Duarte Guimarães

Professora aposentada (UFPR). Doutora em Estudos Literários pela UFPR. Docente e vice-coordenadora do Mestrado em Comunicação e Linguagens da UTP. Autora de Comunicação tecnoestética nas mídias audiovisuais. Porto Alegre: Sulina, 2007. Publicou livros, capítulos, trabalhos em anais e inúmeros artigos.

\section{Resumo}

$\mathrm{O}$ artigo discute a interferência da WEB e da mobilidade no redimensionamento dos padróes perceptivos e na construção da subjetividade contemporânea. Investigam-se expectativas e usos concretos das instâncias de comunicação; bem como suas restriçóes, limites e impactos nas relações interpessoais e no próprio ato de conviver, com o foco na infância e na juventude.

Palavras-chave: Comunicabilidade; Internet; Mobilidade

\section{Abstract}

This article aims at discussing the interference of WEB and mobility in the reconfiguration of human perceptive patterns and in the creation of contemporary subjectivity. Furthermore, the expectation and the real use of the instances of communication are investigated; as well as its restrictions, limits and impacts in the interpersonal relations and in the the idea of to live together, with the focus in the childhood and the youthful.

Keywords: Communicability; Internet; Mobility 


\section{Pré-texto}

O propósito deste artigo é lançar um olhar crítico sobre as redes sociais e as tecnologias móveis, dentre outras formas virtuais de interaçóes pessoais e sociais viabilizadas na cibercultura, com o foco na infância e na juventude. Sua ênfase recai na reconfiguração das relações do sujeito com o seu entorno, que é determinada pela disseminação da cultura multimidiática. Hoje, as dobras sociais são interpenetradas pela lógica digital, o que influencia cada vez mais as formas de relacionamento humano, engendrando processos de subjetivação profundamente transformados e com poderes de produção de uma nova ordem de pensamento.

Dentro de um contexto que cria valores e representaçóes dependentes dos recursos tecnológicos, tem sido bastante estudada a forma como o mundo da propaganda, a cada dia, celebra as novidades do mercado; seja alimentando uma onda consumista de dimensóes e conseqüências inimagináveis, seja contribuindo na produção da subjetividade ou, até mesmo, de uma pseudoconstrução identitária.

Diante da maciça propaganda de produtos informatizados, câmeras digitais, celulares multifuncionais e similares, em julho de 2008, nosso olhar foi atraído por um caso atípico de mensagem publicitária, veículado pela mídia impressa, que toca num ponto fulcral das relaçóes humanas na cena atual. $\mathrm{O}$ referido anúncio serviu de motivação para este artigo, justamente por sua singularidade, ao referir-se à questáo da quantidade e qualidade das relaçóes de

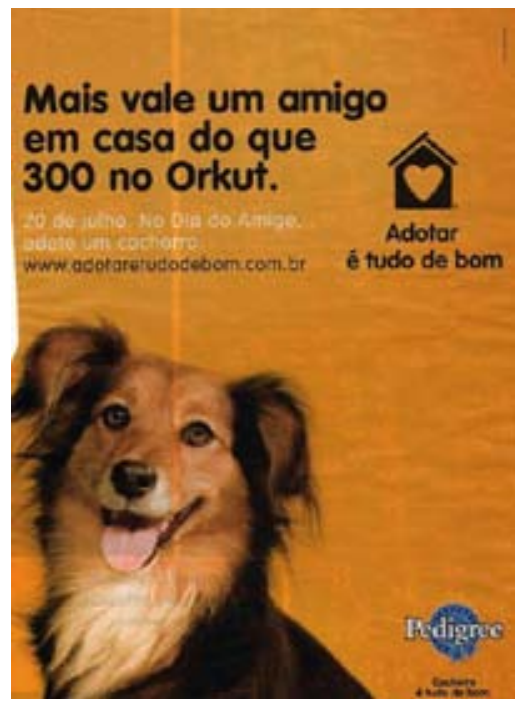

Revista Veja. Ano 41- no. 31.

Sáo Paulo: Ed. Abril. 06/08/2008.

amizade mantidas, principalmente por adolescentes, através das redes sociais; e o faz de forma clara, porém sutil, sem perder as características persuasivas inerentes à divulgação de um determinado produto.

De início, gostaríamos de reproduzir o anúncio de página inteira, publicado em alguns conhecidos periódicos, no mês de julho de $2008,{ }^{1}$ e que serviu de pré-texto ou de texto motivador deste artigo. Trata-se de uma peça publicitária que nos parece extremamente oportuna porque, em sua síntese verbo-visual, aciona elementos sensíveis e afetivos, tornando-se capaz de provocar reflexôes sobre a fragilidade das interaçôes humanas forjadas no âmbito 
das redes, com o evidente prejuízo das relações interpessoais no sentido estrito ou seja, presencial.

Escolhida apenas como um exemplo, que poderia sintetizar as reflexôes a serem desenvolvidadas neste artigo, sem termos a intenção de aqui analisá-la, diríamos que, inteligentemente, a propaganda utiliza-se de formas simbólicas, das quais a ideologia das mídias se apropria (discursos, imagens, iconografias), porém, agindo na contramão das representaçóes massificadas de uma pseudo-construção de um estilo de vida. Desse modo, ela viabiliza elaboraçóes mentais ligadas à afetividade e à subjetividade, vinculando-as a açóes politicamente corretas.

Mais do que ser persuadido a adotar um animal e/ou utilizar determinada marca de ração para cães, acreditamos que a página aqui comentada provoca, de forma inteligente e não dogmática, o leitor a indagar, até que ponto, sob a forte influência da mídia, as pessoas estariam adquirindo uma identidade fugidia e cultivando uma pseudo-convivência nos espaços imateriais das redes sociais.

Logo, nosso objeto de estudo não é o referido anúncio, pois almejamos investigar alguns impactos infocomunicacionais na configuração da subjetividade hodierna, diante da "hipervalorização" das novas tecnologias; procurando verificar de que forma elas se incorporam ao cotidiano dos indivíduos, manipulando-os e impondo seus valores, tanto no terreno da razáo, quanto em termos da pura percepção. Nossa premissa básica é que os avanços tecnológicos ligados ao uso das redes telemáticas, através de dispositivos móveis ou de sites de relacionamento, engendram uma nova arquitetura na tessitura social, redimensionando comportamentos nos sujeitos envolvidos em processos comunicacionais.

Procurando melhor entender o quadro que se desenha atualmente, investigaremos expectativas e usos concretos dos meios de comunicação, bem como problematizaremos suas restriçôes/limites e imposiçôes, principalmente no que tange às geraçóes mais jovens, com suas práticas comunicativas peculiares e processos de relacionamento, tanto através dos telefones celulares quanto da Internet.

\section{Um novo sensorium e a reconfiguração da subjetividade con- temporânea}

Diante dos exercícios cotidianos de simulações identitárias permitidos pela revolução digital, sentimentos de pertencimento e identidades culturais alteram-se a cada dia, por força das inusitadas relaçóes espaço-temporais vivenciadas contemporaneamente, o que têm afetado a percepção do próprio sujeito em relação a si e aos outros.

Para André Parente,

As redes tornaram-se ao mesmo tempo uma espécie de paradigma e de personagem principal da mudanças em curso justo no momento em que as tecnologias de comunicação e informação passaram a exercer um papel estruturante na nova ordem mundial. (...) Nada parece escapar às redes, nem mesmo o espaço, o tempo e a subjetividade. (PARENTE, 2007, p. 101) 
A mobilidade é o outro tópico a ser considerado, com relevos comportamentais distintos, quando se trata da linguagem da comunicação contemporânea e seus mecanismos de articulação de sentidos. Com as expectativas e usos concretos das tecnologias móveis, bem como suas restriçóes e limites, não é difícil perceber seus impactos nas relações interpessoais e no próprio ato de conviver, na urgência de um mundo globalizado.

As modificações provenientes da aliança entre as telecomunicações e a informática tem repercutido nas manifestaçôes culturais de modo acentuado, como um novo enciclopedismo associado à incorporação das tecnologias de ponta. Nunca tanta informaçáo esteve táo facilmente ao alcance de tantas pessoas, quanto na "civilização do mosaico eletrônico", de McLuhan, ou hoje, naquilo que Martín-Barbero (2001) denomina "mosaico artesanal do habitar".

O autor espanhol lembra como Walter Benjamin chegou à relação da massa com a cidade através da obra de Baudelaire ${ }^{2}$ e sua poética experiência da multidão, responsável pela "expressão de um novo modo de sentir, das massas, com seu novo sensorium e seu contraditório sentido.” (MARTÍN-BARBERO, 2001, p. 90-91) Para ele, o pensador frankfurtiano, ao debruçar-se sobre a era da reprodutibilidade técnica, mais do que de arte ou de técnica, trata da forma como se produzem transformaçóes na experiência humana: interessam-lhe o modo e a maneira de percepção sensorial, ou seja, as mudanças da sensibilidade.

Nessa linha de raciocínio, lembramos que a multifragmentação social foi se evidenciando gradativamente, nos últimos cem anos, para configurar-se mais agudamente nas manifestaçóes da contracultura e posteriormente, com os neo-hippies, punks, darks, yuppies e outros grupos semelhantes ganhando espaço na cena urbana finissecular. Neste cenário, a crise da modernidade e as polêmicas em torno da pós-modernidade alimentaram um mal estar diante de um novo fin $d u$ siècle, utilizando-se da mídia para conseguir ganhar visibilidade no espaço público, onde permeiam as relaçóes sociais. Nesse contexto, os meios de comunicação passam a ter a função essencial de manter a coesão e visibilidade de cada grupo social em questão.

Diríamos que, hoje, a informação não mais se move segundo os ditames da comunicação, mas em função do aparato tecnológico da globalização, numa velocidade assombrosa. Tudo é instantâneo, imediato, sendo que a essência da informação veiculada pelas mídias é um conjunto de impressões, de sensaçóes voláteis e fragmentadas. Digital e virtual atravessam os limites entre os signos e os objetos do mundo, no hibridismo dos multimeios, como explica Parente, ao retomar o pensamento de Latour (2004):

Para Latour, de fato, os hibridos emergem da rede como intermediários entre os elementos heterogêneos objetivos e subjetivos, sociais e tecnológicos, saberes e coisas, inteligências e interesses, em que as matérias e as subjetividades são trabalhadas, forjadas, fundidas sem o controle dos métodos ditos objetivos da ciência. (PARENTE, op. cit. p. 104)

Entendemos que, com a apropriação do comando digital, as habilidades nessas novas linguagens possibilitam a inserção do sujeito numa esfera 
privilegiada de conhecimento, além de apontar para o redimensionamento do espírito investigativo e da imaginação criadora na cibercultura. Por outro lado, quando passam a signos de poder e de status, tais habilidades não só alteram profundamente as formas de comunicação e expressão, como podem acabar por se constituírem numa celebração/ostentação da trivialidade, da irrelevância e da imponderabilidade.

Nesse sentido, o fio condutor de nosso raciocínio prende-se à idéia de verificar de que forma meios, códigos e linguagens multiplicam-se e hibridizamse, ao operarem com resultados extremos da tecnologia, vendo-se, portanto, obrigados a romper com a antiga oposição entre o pensamento simbólico e o pensamento técnico. É importante considerar a força com que os novos meios de veiculação de mensagens exercem influência na socialização e na subjetividade, uma vez que a as tecnologias digitais introduzem elementos inéditos, tanto vivenciais quanto estéticos, em nossa cultura informatizada.

Hoje, intensificados na globalizaçáo, que alimenta as possibilidades de expansão das paisagens urbanas e anula as perspectivas espaciais em favor de uma dimensão multifacetada, os contornos das cidades são expandidos para além das barreiras geográficas e físicas. Segundo Nestor Garcia Canclini, surgem as "megacidades" ou seja,

\footnotetext{
(...) espaços onde se apaga e torna incerto o que antes se entendia por 'lugar'. Não são áreas delimitadas e homogêneas, mas espaços de interação em que as identidades e os sentimentos de pertencimento são formados com recursos materiais e simbólicos de origem local, nacional e transnacional. (CANCLINI, 2003, p. 153)
}

Como resultado, redimensiona-se a experiência de habitar e pertencer, simultaneamente, a lugares variados em permanente rearticulação. Assim é que a megacidade estatue-se como um "não-lugar", ou seja, incorpora a possibilidade de um pertencimento fluido a muitos lugares.

Assim é que a urgência da urbe do século XXI mostra-se marcada pela profusão de signos comunicacionais, oriundos dos mais diversificados fluxos, sejam eles comerciais, sociais e/ou principalmente culturais.

\section{A reorganização das interações sociais: sense and sensibility}

Pensando a cultura como uma rede em estado de permanente abertura, que se altera na dinâmica das produçóes de sentido, estabelecida por meio das trocas comunicativas, lembramos que, para o pensador russo Mikhail Bakhtin (2002), a enunciação produtora de sentidos não existe fora de um contexto sócio-ideológico, em que cada locutor tem um "horizonte social" bem definido, pensado e dirigido a um auditório social também definido. Logo, a enunciação é o produto da interação de dois indivíduos socialmente organizados, pois sua natureza é social.

No entanto, diante do sentido de urgência e do fragmentarismo, ligados ao culto da velocidade nas metrópoles modernas e pós-modernas, julgamos pertinente identificar na cena atual uma espécie de "polifonia" urbana, na acepção que Bakhtin confere ao termo, por volta de 1930. Para o autor, o 
gênero polifônico apresenta diferentes vozes sociais que se defrontam, se entrechocam, se contradizem, manifestando diferentes pontos de vista sociais sobre um dado objeto, porém de forma infinita e inconclusa.

Neste caso, poderíamos imaginar o cenário urbano como um romance de Dostoiévski (estudado por Bakhtin), que apresentaria "contradições irremediavelmente contraditórias", pois não há superação dialética dos conflitos desenvolvidos na trama. O romance polifônico de Dostoiévski não se resolve, não há síntese, não atinge uma apoteose: "a multiplicidade de vozes e consciências independentes e imiscíveis e a autêntica polifonia de vozes plenivalentes constituem, de fato, a peculiaridade fundamental dos romances de Dostoiévski." (BAKHTIN, 2002, p. 4) Para o teórico russo, a essência da narrativa polifônica reside na inconclusibilidade.

Tendo em vista a inconclusividade dos processos comunicacionais e a contínua emergência de contradiçóes insuperáveis na cena atual, entendemos que, para dar prosseguimento às reflexóes aqui desenvolvidas, faz-se necessário problematizar aspectos, não tão positivos, em relação aos modos de convivência humana. Se, no transcurso do século XX, as facetas multiformes da comunicabilidade espelham uma vasta sinopse espaço- temporal, que amplia o leque de perspectivas para muito além do jamais visto; no contexto hodierno, a variedade e o amplo espectro de sensaçôes urbanas levam a imaginação humana a operar sob tensão, diante da percepção de uma nova duração: a sincronia, ou seja, tudo ao mesmo tempo. Excesso de imagens, muitas informaçôes, muitos sons e um já famoso stress, marcam o habitante da cidade grande, diante de uma infinidade de solicitaçóes, todas urgentes: a urbe urge.

No que tange às geraçôes mais jovens, o sentido das práticas interacionais sociais parece emergir do confronto com a fragilidade evanescente e os limites materiais, o que leva à valorização daquilo que está além do visível ou da memória corporal externa. Polifonicamente, diria Bakhtin, a multiplicidade de vozes e consciências independentes e imiscíveis, configuram os processos enunciativos inconclusos. Poder-se-ia, no extremo, falar de incomunicabilidade, já que o processo de convivência social ou mesmo familiar, muitas vezes, não ultrapassa tentativas de traduzir um turbilhão de situaçóes internas mal assimiladas.

\section{As formas evanescentes de comunicabilidade e o adiamento in- finito da presença}

Centrando nosso foco em hábitos e comportamentos de parcela significativa da juventude, e, até mesmo da infância, num país em desenvolvimento como o Brasil, percebemos a hegemonia dos modos virtuais ou imateriais de produção simbólica, em detrimento da presença física.

Diante das inumeráveis vantagens das conquistas tecnológicas, consideradas como imprescindíveis à comunicação e à organização da vida hodierna, torna-se relevante investigar as múltiplas e, por vezes, paradoxais, possibilidades de manipulação e de intervenção nas mensagens midiáticas - o que apontaria para o outro lado da moeda, ou seja, para seus possíveis problemas. 
A primeira questão que se coloca é como a compulsão pelo movimento e a concentração de múltiplas experiências no tempo são radicalmente valorizadas; basta observar como os dispositivos das redes telemáticas alteram profundamente o conceito de lugar fixo, agora substituído pelo espaço dos fluxos com toda sua imponderabilidade.

Como diversos autores contemporâneos apontam a relação direta entre mobilidade e desterritorialização, apenas para ilustrar o exposto, tomamos como exemplo o recente estudo "Mobilidade Brasil 2008", da multinacional francesa de pesquisa Ipsos ${ }^{3}$, que busca, principalmente, compreender de que maneira o celular modificou a vida e o comportamento dos usuários, em termos de novas atividades e costumes. A pesquisa revela como os aparelhos celulares estáo mudando o comportamento dos brasileiros, tendo detectado a existência de muitas pessoas que não conseguem separar-se de seu telefone celular, nem por um segundo. Para a maioria das pessoas, todas maiores de 16 anos, um tempo suportável sem o aparelho é de, no máximo, um dia! O fato é que até mesmo as crianças tem revelado, cada vez mais, o mesmo tipo de dependência, o que comentaremos na sequência deste artigo.

Diante de dados como os acima, nossa abordagem, que não se pretende nem "apocalíptica", nem "integrada" (ECO, 1976), muito menos "essencialista”, mostra-se interessada, sim, nas mutaçôes culturais produzidas pelos avanços tecnológicos, seja nas relaçôes familiares, seja na amplitude dos processos comunicativos interculturais.

Se o impacto da eletrônica provocou um deslocamento do eixo dos processos de comunicação, impondo a expansão dos horizontes culturais conhecidos e a consequente reavaliação das estratégias comunicativas; hoje, a revolução digital e a fusão das mídias vem provocando deslocamentos culturais, a ponto de não podermos negar que a instabilidade e a transitoriedade se transformaram em "marcas" do nosso tempo.

Se, no âmbito das relações familiares, elementos ligados à socialização primária redimensionam-se a cada dia, nem sempre de forma positiva no que tange à necessidade humana de convivência, o mesmo pode ser ampliado para práticas comunicativas imateriais e evanescentes, como por exemplo as "conversas" ou as "amizades" mantidas exclusivamente no âmbito das redes. Tudo é virtualizado, de modo a fornecer uma ilusão de relaçóes interpessoais nas comunidades virtuais, o que nos leva de volta à alusão aos "amigos reais e virtuais" feita no anúncio que serviu de ponto de partida para as reflexóes desenvolvidas neste artigo.

Trata-se de um adiamento infinito da presença física; e, até mesmo os adultos acabam se rendendo. Antes, visitávamos os amigos, depois, passamos a falar ao telefone, hoje, trocamos e-mails, por ser mais rápido e prático. A ilusão da imediaticidade está no cerne do que significa ser atual, mas na verdade, leva a uma abdicação da experiência do próprio presente: tudo é transitório e fugaz, principalmente nas grandes cidades do século XXI. O medo de náo conseguir captar o fluxo hiperbólico das demandas tecnológicas e comunicacionais, onde "tudo passa o tempo todo", vai imprimindo uma aguda consciência temporal, 
principalmente às geraçóes maduras. Por outro lado, obviamente, os mais jovens são os mais propensos a aderirem inteiramente às novas formas de comunicação e expressão, com todo entusiasmo e energia que lhes são próprios - o que nos leva a algumas indagaçóes:

- Estariam as crianças e os adolescentes conscientes do esgarçamento das relaçóes interpessoais, quando se opta pelas mensagens e conversas nos celulares e por amizades não presenciais nos sites de relacionamento?

- Em que medida a subjetividade estaria sendo reformatada pelo relacionamento social nas redes, em detrimento do face-a-face, do olho no olho, da mão na mão?

\section{Representações midiáticas da infância e da adolescência}

Sob a forte influência da mídia, em sua acepção mais ampla, incorporando-se ao cotidiano dos indivíduos, manipulando-os e impondo seus valores, tanto no terreno da razão, quanto em termos da pura percepção, as pessoas estariam adquirindo uma identidade fugidia. Perante os conflitos identitários decorrentes de uma espécie de "mistificação" ou de uma "mitificação" da realidade virtual, da inteligência artificial, da robótica e de outros inventos, indiscutivelmente, as relaçôes interpessoais e sociais estariam sendo afetadas. Há dez anos, Stuart Hall referia-se à crise do indivíduo pós-moderno que reflete as mudanças que "deslocaram as estruturas e processos centrais das sociedades pós-modernas, abalando os quadros de referência que davam aos indivíduos uma ancoragem estável ao mundo social" (HALL, 1999, p.9)

Os decorrentes conflitos geracionais tenderiam, portanto, a crescer, principalmente no que tange aos valores e à construção da subjetividade. Ao manipular mais imagens e signos do que coisas, a chamada "geração digital" ou "geração multitarefas" cultivaria a trivialidade e a superficialidade.

Lúcia Santaella trata exemplarmente do tema, em seu artigo do livro IMAGEM (IR)REALIDADE), mais especificamente quando fala das "imagens voláteis: ubíquas, nômades, triviais”, contrapondo as fotografias tradicionais - próprias dos momentos significativos da vida, de comemoraçóes ou eventos a serem rememorados - às imagens voláteis - que se destinam a registrar qualquer momento, por mais insignificante que seja.

Enquanto os tradicionais instantâneos fotográficos eram frutos de escolhas, até certo ponto refletidas sobre o enquadramento, o ponto de vista, a proximidade ou distância em relação ao objeto ou situação, as imagens voláteis sãos instantâneos capturados ao sabor de circunstâncias imponderáveis, sem premeditação, sem preocupaçôes com a relevância do instante ou com a qualidade do resultado. Fotos digitais podem ser apagadas sem ônus e imediata e indefinidamente repostas por outras.[...] todo o visivel se tornou reprodutivel. Além de reprodutivel, portátil. Além de portátil, fluido. (SANTAELLA, 2006, p. 199-200)

Consideramos que tais assertivas podem ser expandidas a outras esferas dos sistemas de representação, o que explicaria porque, em nossa época, as identidades (compreendidas como heterogêneas, híbridas e múltiplas) podem 
ser vistas como performances contingenciais, que abrigam incertezas, indagaçôes e questionamentos cotidianos do ser humano.

Efeitos similares podem ser identificados no que tange às trocas simbólicas viabilizadas pela globalização, que produz um "supermercado" mundial de imagens, linguagens e estilos transterritoriais e multilinguísticos. Desta mudança nos processos de subjetivação vai eclodir o fenômeno das identidades sem lugar fixo e temporalmente desvinculadas ou desorientadas, como explica Stuart Hall:

$$
\begin{aligned}
& \text { [...] quanto mais a vida social se torna mediada pelo mercado global de estilos, lugares } \\
& \text { e imagens, pelas viagens internacionais, pelas imagens da mídia e pelos sistemas de } \\
& \text { comunicação globalmente interligados, mais as identidades se tornam desvinculadas } \\
& \text { - desalojadas - de tempos, lugares, histórias e tradiçöes especificos e parecem flutuar } \\
& \text { livremente". (HALL, 2002, p. 75). }
\end{aligned}
$$

Segundo Santaella, a invasão de imagens triviais na vida das pessoas seria "inofensiva, mas, ao mesmo tempo, onipresente, paradoxalmente onipotente e sem importância.” (SANTAELLA, 2006, p. 200).

Obviamente que a cultura juvenil na era digital recebe os impactos deste estado de coisas. Joáo Freire Filho e Joáo Francisco Lemos, em estudo recente sobre reportagens que abordam questóes geracionais, advertem sobre o modo como as novas formas de comunicaçáo e de sociabilidade dos jovens são celebradas, bem como são consideradas extraordinárias suas aptidões ao manejarem as máquinas.

Ao indicarem os aspectos sociais que afetam a condição juvenil no contexto contemporâneo, as reportagens que traçam o perfil da "Geração Digital" enfatizam os desafios a serem contornados, preferindo enaltecer potencialidades e aptidóes em vez de discutir as origens e implicaçóes sociais e politicas destas mudanças. (FILHO e LEMOS, 2008, p. 23)

Os autores analisam matérias jornalísticas brasileiras que tratam de alguns emblemas geracionais, tais como "Geração Internet", "Geração Conectada", entre outros, no ensaio recente: "Imperativos de conduta juvenil no século XXI: a "Geração Digital” na mídia impressa brasileira”. (2008) Segundo eles, os retratos midiáticos da juventude atual são normativos, ou seja, reforçam os modelos pragmáticos da preparação para a configuração do capitalismo contemporâneo.

Concordamos com essa visão, quando os autores consideram a conexão frenética a diferentes telas, nas novas práticas comunicacionais validadas pela imprensa atual, como um novo modo de gerir a vida em favor de um capitalismo flexível e do consumismo. A nosso ver, isso explicaria a necessidade constante de trocar de celular, do MP3, 4, 5, 6 ou 7 para MP8; ou ainda a "aflição" das crianças diante de constataçóes tais como: "Meu Play Station já está superado."! Por outro lado, parece-nos mais relevante ainda a reformatação dos comportamentos, dos hábitos e da percepção infanto-juvenis sobre o estar no mundo. 
O exposto leva-nos a novas reflexôes sobre como os jovens se comunicam, na cena atual e, também, à reportagem "Tudo ao mesmo tempo - e agora” (Revista Veja, 06/08/2008), que, além de corroborar as idéias do referido ensaio, mostra-se de certa forma, um pouco assustadora, pois trata de uma faixa etária entre 6 a 14 anos, com o apelo do subtítulo: "Pelo computador e pelo celular, as crianças conversam com vários amigos, jogam videogame e ainda discutem com os pais. Agora você pelo menos sabe o nome disso: seu filho é multitarefas". (Idem, p. 93).

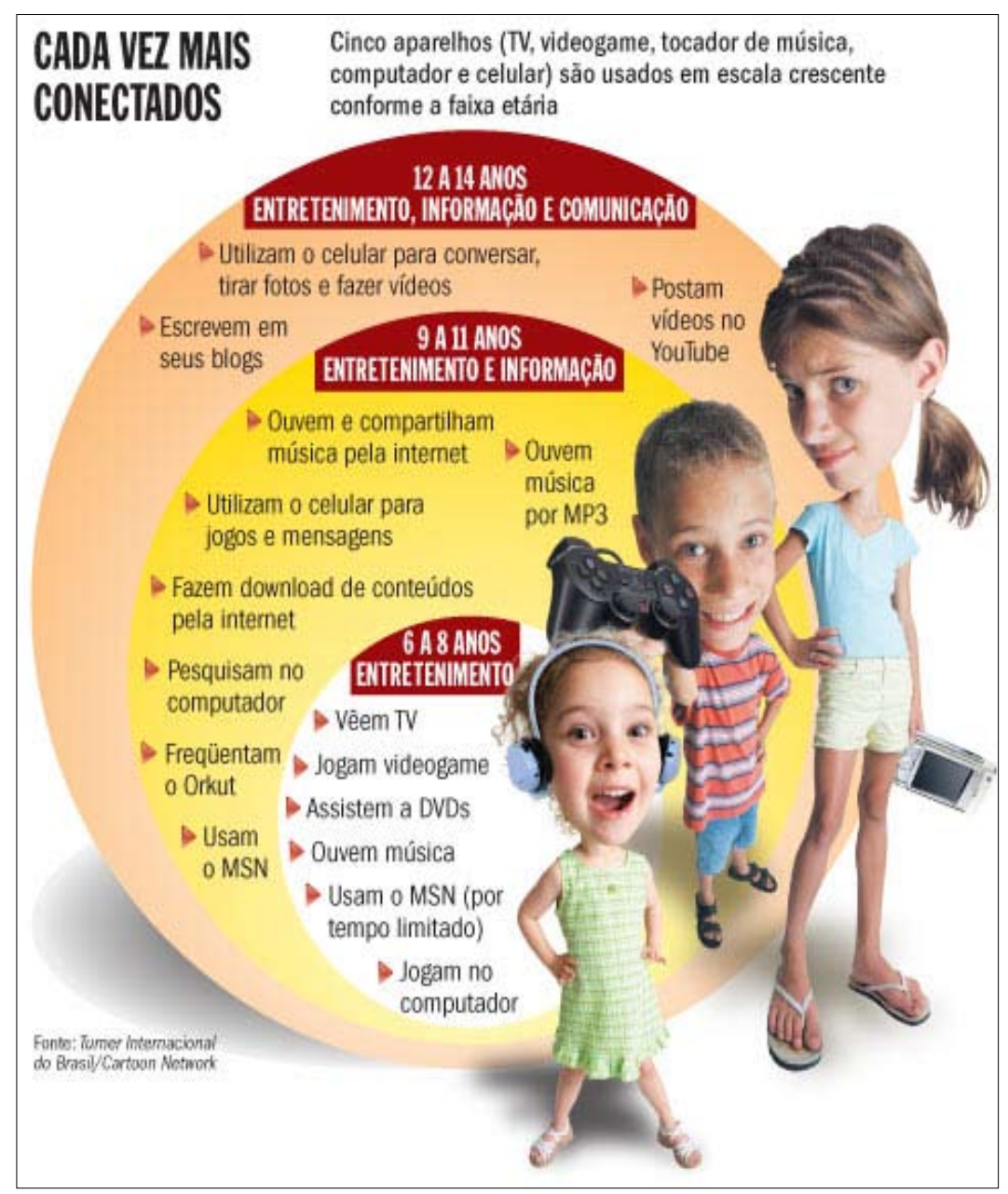

fonte: www.vejaonline.abril.com.br

Os argumentos têm o endosso de especialistas consultados, de pais entrevistados e das próprias crianças, além de fontes da $W E B$, como mostra o quadro acima.

O quadro informativo que aparece na página seguinte da reportagem, leva-nos a refletir sobre o tipo de atitude padrão no tratamento dado pelas diferentes mídias ao tema: por um lado, um entusiasmo exagerado diante do uso dos equipamentos digitais e suas infinitas potencialidades expressivas; mas por outro lado, perplexidade e incerteza quanto ao seu impacto no futuro das crianças e jovens hiper-conectados. Afinal, sabemos que nada substitui a relação pessoal, através da qual a criança aprende a trabalhar em equipe, a lidar com as frustraçóes e perdas, em suma a conviver, no sentido de saber compartilhar suas vivências presencialmente com outros indivíduos. 
O subtítulo diz tudo: "Elas não saem da rede”. Diante dos dados, por vezes surpreendentes, a metade final da reportagem assume um outro tom, ao apontar os pontos negativos e as limitaçóes da vida virtual, tanto no seio da família quanto na escola, para concluir com opinióes abalizadas sobre os perigos/custos da rapidez e da multiplicidade, ou sobre o desconhecimento das conseqüências futuras de tanta pressão sobre as crianças, para que sejam mais velozes.

Dentre os problemas aventados pela reportagem, parece-nos de suma importância a questâo da crescente dificuldade de relacionamento pessoal. Acreditamos que, tal como muitos adolescentes das grandes cidades, as crianças de hoje tendem à evasão, através das inúmeras telas à sua disposição. Seriam pequenos ermitãos cibernéticos, paradoxalmente com suas windows (janelas) permanentemente abertas para o mundo virtual?

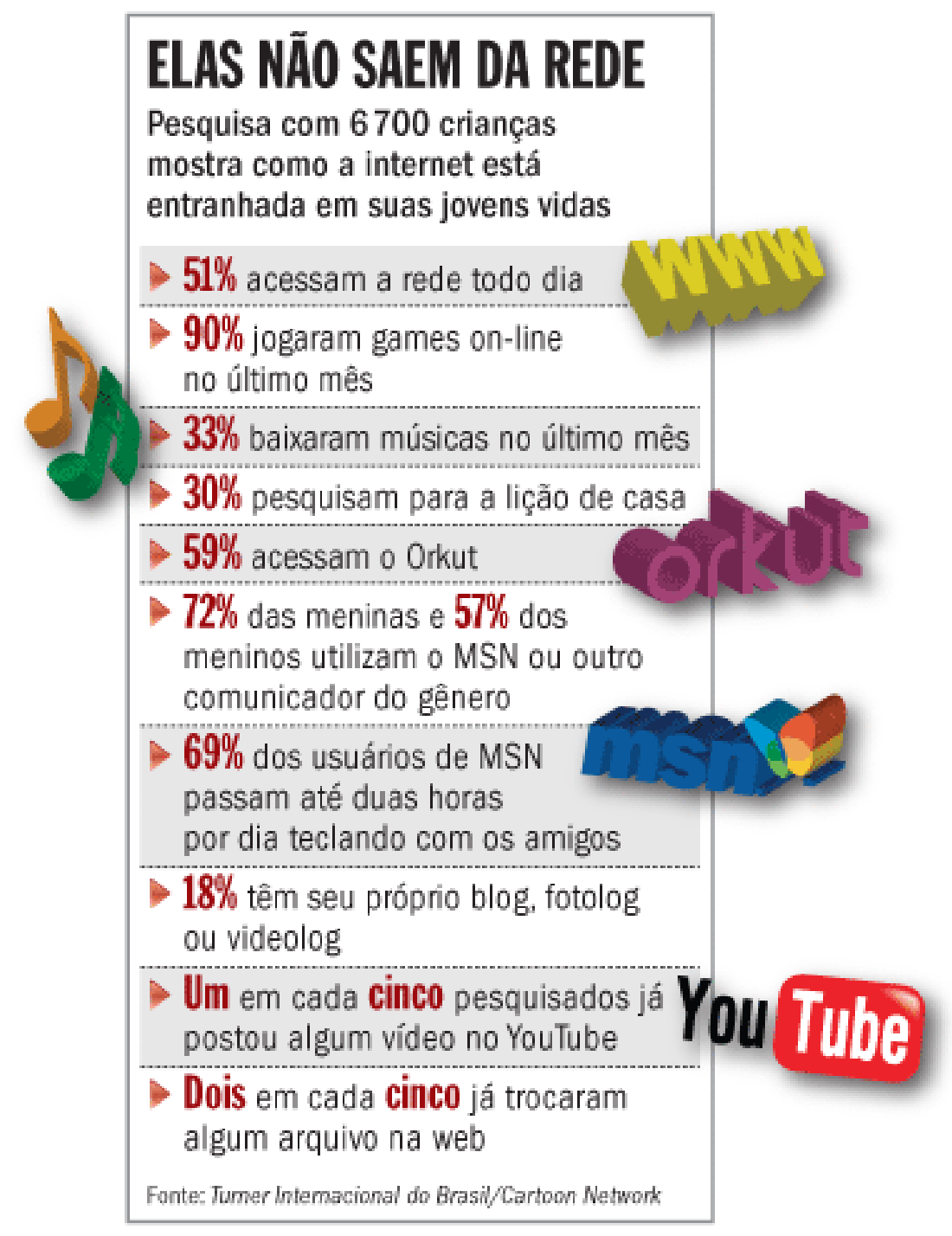

fonte: www.vejaonline.abril.com.br

\section{À guisa de conclusão}

Acreditamos que, no momento em que as interaçóes sociais passam a ser regidas pelo presenteísmo e pela efemeridade, o sujeito fragmentado encontra maior facilidade de apresentar-se como persona (etimologicamente máscara), 
numa espécie de theathrum mundi das identidades fugazes e intangíveis. Obviamente, as crianças e os adolescentes seriam os mais afetados, com seus perfis reconfigurados continuamente e de forma aleatória na virtualidade das redes sociais e nos telefones celulares.

Nossas reflexões encaminham-se, portanto, para confirmar que os impactos da comunicação tecnologicamente mediada alteram significativamente os mecanismos de articulaçáo de sentidos e os modos de convivência, agora reformatados pelos avanços tecnológicos. Por outro lado, acreditamos que refletir sobre as redes "sociotécnicas" (PARENTE, 2007), com seus hábitos e seus apegos, serve principalmente para suscitar indagaçóes sobre a construção da subjetividade e os conflitos identitários na contemporaneidade, num momento em que a atualização do self vê-se completamente liberada, ultrapassando os limites da identidade e do indivíduo.

Inegável é que tanto nas práticas sociais quanto nas afetivas, em seus inumeráveis e complexos processos interacionais, podemos constatar efetivas transformaçóes não só dos pilares infra-estruturais da comunicação, mas também dos fundamentos da socialidade. Com o foco na sociedade pósindustrial, André Lemos explica

A desterritorialização informacional afeta a política, a economia, o sujeito, os vínculos identitários, o corpo, a arte. A internet é, efetivamente, máquina desterritorializante sob os aspectos político (acesso e ação além das fronteiras), econômico (circulação financeira mundial) cultural (consumo de bens simbólicos mundiais) e subjetivo (influência global na formação do sujeito). (LEMOS, 2007, p. 282)

Afinal, quando se trata da cibercultura, cumpre relativizar tais questóes. No Livro da XV COMPÓS, Lemos, ao explicar que o argumento central de seu capítulo gira em torno da idéia de que o ciberespaço e as tecnologias móveis criam novas reterritorializaçóes, reconhece que estamos em meio a uma cultura da conexão generalizada, cujos processos de territorialização e de desterritorialização são potencializados pelas tecnologias móveis. "Como espaço estriado, o ciberespaço é, no entanto, desterritorializado por agenciamentos maquínicos, sociais e coletivos, criando reterritorializações. Essa é a dimensão comunicacional, social e política da cibercultura.” (op. cit. p. 283)

Acreditamos que, por um lado, a interatividade viabilizada pelo conceito fractal de um espaço-tempo vetorizado permite a integração de elementos que antes se encontravam separados - o que realmente marca positivamente as práticas sociais e a vida das pessoas. Por outro lado, por não se tratar de interação face-a-face e, num contexto de co-presença, tais formas de relacionamento nãopresenciais podem alterar-se a cada instante e tomar caminhos imprevisíveis, o que, sem dúvida, demanda por novos estudos sobre as possíveis formas de subjetivaçóes tramadas em rede, nas quais os perfis são desprovidos de substância material e não mais precisam identificar-se a referências estáveis. 


\section{Notas}

${ }^{1}$ No Dia do Amigo, a Lew/LaralTBWA veiculou um anúncio criado para a raçáo PEDIGREE, que incentiva as pessoas a adotarem um cáo. $\mathrm{O}$ título da peça é: Mais vale um amigo em casa do que 300 no orkut.

Além do anúncio, foi criado também o projeto "Adotar é Tudo de Bom", dando continuidade à campanha on line criada pela IDITBWA, no site http://www.adotaretudodebom.com.br

2 Remeto o leitor interessado no tema, aos meus artigos: GUIMARÁES, Denise A.D. "A arte na urgência da urbe".Revista eletrônica e-letras. Curitiba: UTP, v.3, p.01 16, 2001 e "Baudelaire e a poesia da cidade moderna". Revista eletrônica e-letras. Curitiba: UTP, v.10, p. 01 - 14, 2005.

3 A pesquisa foi realizada em maio de 2008 , sob a forma de 1.000 entrevistas com ambos os sexos, acima de 16 anos, em 70 cidades e 9 regióes metropolitanas. O estudo revela que $18 \%$ dos brasileiros se dizem viciados em seus celulares. As mulheres e os jovens com idade entre 16 e 24 anos são os mais viciados em seus aparelhos. Como se não bastasse, $5 \%$ dos respondentes utilizam mais de uma linha regularmente. $\mathrm{Na}$ classe $\mathrm{AB}$, este número sobe para $17 \%$. A pesquisa ainda detectou que existem pessoas que não conseguem separar-se de seu celular nem por um segundo. Para a maioria das pessoas, um tempo suportável sem o aparelho é de, no máximo, um dia. Um em cada cinco brasileiros se sente abandonado quando não recebem nenhuma ligação ou mensagem durante o dia. Especialmente entre as mulheres (23\% contra $15 \%$ dos homens) e principalmente os jovens. (Fonte www.overload blog.br. Acesso 20 de nov. 2008)

\section{Referências bibliográficas}

BAKHTIN, Mikhail. Marxismo e filosofia da linguagem . São Paulo: HUCITEC, 9a ed. 2002.

CANCLINI, Nestor Garcia. Culturas Hibridas. São Paulo, Edusp, 2003.

ECO, Umberto. Apocalípticos e Integrados. São Paulo: Perspectiva, 1976.

FREIRE FILHO, João e LEMOS, João Francisco. "Imperativos de conduta juvenil no século XXI: a "Geração Digital” na mídia impressa brasileira.” Revista Comunicação, Mídia e Consumo. São Paulo: ESPM. V. 05, n.13, jul. 2008, p. 11-25.

HALL, Stuart. A identidade cultural na pós-modernidade. Rio de Janeiro: DP\&A Editora, 2003.

LEMOS, André. "Ciberespaço e tecnologias móveis. Processos de Territorialização e Desterritorialização na cibercultura”. In: IMAGEM. VISIBILIDADE E CULTURA MIDIÁTICA . Livro da XV COMPÓS. Ogs. MÉDOLA, Ana Sílvia Davi; ARAÚJO, Denize Correa; BRUNO, Fernanda. Porto Alegre:Sulina, 2007.

MARTÍN-BARBERO, Jesús. Dos meios às mediaçóes: comunicação, cultura e hegemonia. Rio de Janeiro: Ed.UFRJ, 2001. 
PARENTE, André . "Rede e subjetividade na filosofia francesa contemporânea . In: RECIIS - Revista Eletr. de Com. Inf. Inov. Saúde. Rio de Janeiro, v.1, n.1, jan.-jun., 2007. p.101-105.

SANTAELLA, Lúcia ."Por uma epistemologia das imagens tecnológicas: seus modos de apresentar, indicar e representar a realidade."In: ARAUJO, Denize Correa (org) Imagem [i]realidade. Comunicação e cibermidia. Porto Alegre Sulina, 2006. p. 173-201.

VEJA. Ano 41- no. 31. São Paulo: Ed. Abril. 06/08/2008. 